\title{
An Investigation into Slipping Adhesion between Rails and Wheels*
}

\author{
by Kazuhiko NAGASE**
}

\begin{abstract}
Quantitative analysis of the phenomena of adhesion between the rails and wheels is essential to properly control the behaviour of rolling stock. However, most of those investigations have been carried out in many countries. rate of slipping has investigations have been made in laboratory rooms, the data obtained in them have not newithin the minute range of creep, and the data obtained in them have not necessarily been in good compatibility with
those of the field tests.

In view of such situations, the author designed and constructed a test truck based on an entirely new idea, and ran a passenger car equipped with distance was not long, thest track in JNR Ohmiya Factory. Although the test along the direction of the real state of the adhesion changing continuously has been clearly reproduced.
\end{abstract}

Key Words Railways, Adhesion, Slipping Adhesion, Rails and Wheels

\section{Introduction}

The coefficient of slipping adhesion $\mu^{\prime}$ which represents the state of forces acting between the rails and wheels while a railway car is running - including the racing and skidding - bears profound meanings quantitatively. Therefore, since the initiation of research by F. W. Carter", a large number of investigations have been carried out also in Japan ${ }^{2}$ ) on this subject. However, many of those investigations were made in laboratory rooms with the rate of slipping $n$ limited within the minute range of creep, and only a few results have hitherto been reported on the railway cars currently used. Such a state of things might have been because of the difficulty in measuring $\mu^{\prime}$ at the high rate of slipping $(n=-10 \%)$ experienced in the actual racing or skidding.

In recent years, new methods were proposed by Seki ${ }^{3}$ and Nagase et al.45) to positively control the powered running or braking for utilizing the wheel slip which so far has been regarded as undesirable. For the effective use of such methods, correct understanding of $\mu^{\prime}$ is essential. However, even though the analysis of $\mu^{\prime}$ has long been urged, almost nothing has yet been known about its true state due to the above mentioned difficulty in measurements. The authors and others have already proposed a new idea that would facilitate the detection of $\mu^{\prime}$, recently constructed a "slipping adhesion test truck" based on the proposal and carried out some tests in a factory yard. Although the test distance was not long, some aspects of the true state of in the running car have been clearly reproduced.

* Received: April 18, 1985.

** Senior Researcher, Railway Technical Research Institute (RTRI), Japanese National Railways (2-8-38 Hikaricho, Kokubunji, Tokyo 185, Japan).

\section{Principle of the Slipping Adhesion Test Truck}

In the bogie truck with two axles mechanically connected by means of gears, propeller shafts, etc. (speed ratio of the axles $=1: 1)$, a difference between the diameter of wheels on one axle and that of wheels on the other axle generates the socalled "Conflict torque" between the axles while running ", and gives extra load on the connecting mechanism. Accordingly, strict control is necessary to prevent such a difference in wheel diameters.

If some difference is intentionally given between the diameter of wheels on one axle and that of those on the other. slipping occurs between the rails and the wheels on one or both of the axles while running. However, if a substantial difference is given between the loads on those axles, slipping will take place only at the wheels on the axle under minor load (hereafter called "slipping axle"). Under such circumstances, if the wheels on the slipping axle are made smaller than those on the other axle (hereafter called "Normal axle") skidding will be caused. If the wheels on the slipping axle are larger, racing will take place.

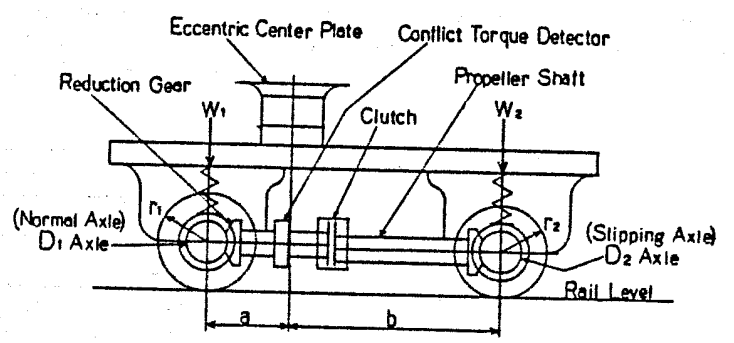

Fig. 1 Design principle of the test truck

Figure 1 shows the design principle of the test truck, wherein $D_{1}$ and $D_{2}$ are the normal and slipping axles respectively. 
They are connected by reduction gears and propeller shafts coupled by a clutch. As above mentioned, load $W_{1}$ on the axle $D_{1}$ must be larger than the load $w_{2}$ on the axle $D_{2}\left(W_{1}>W_{2}\right)$, axis of the center plate should be set at the distance $a$ from the axis $D_{1}$ shorter than the distance $b$ from the axis $D_{2}(a<b)$. In order to cause racing or skidding of the axle $\mathrm{D}_{2}$, wheel radius $r_{2}$ should be larger or smaller than the radius $r_{1}$.

When the truck is run under the slipping adhesion of the axle $D_{2}$, the conflict torques $T_{1}$ and $T_{2}$ are generated on the axles $D_{1}$ and $D_{2}$ respectively, and the tangential (adhesion) force $F_{1}$ is induced at the contact points of the rails and the wheels on axle $D_{1} . T_{1}, \dot{T}_{2}$ and $F_{1}$ are correlated by the following equations.

$$
\begin{aligned}
& T_{1}=F_{1} \cdot r_{1} \cdot \ldots \ldots \ldots \ldots(1) \\
& T_{2}=r_{2} \cdot W_{2} \cdot \mu^{\prime} \ldots \ldots \ldots \text { (2) }^{\prime}
\end{aligned}
$$

If the frictional loss in the driving system can be neglected, $T_{1}$ becomes equal to $T_{2}$. and $\mu^{\prime}$ is expressed as follows.

$$
\mu^{\prime}=\frac{1}{W_{2}} \cdot \frac{1}{r_{2}} \cdot r_{1} \cdot F_{1} \cdots \text { (3) }
$$

The conflict torque $F_{1} \cdot r_{1}$ in both axles can be obtained from the torsional stresses in the propeller shaft etc., and $w_{2}$ is the load on the slipping axle. Neglecting the creep of normal axle, the rate of slipping of the axle $D_{2}$ is expressed by

$$
n=\frac{r_{1}-r_{2}}{r_{1}} \quad \ldots \ldots \ldots \text { (4) }
$$

The axle $\mathrm{D}_{2}$ continues to run slipping in this condition, and $\mu^{\prime}$ can be measured continuously over the whole speed range under the above rate of slipping. Accordingly, the real state of running on main lines which has hitherto been regarded as extremely difficult to grasp can also be readily disclosed.

The retarding force $R$ due to the slipping run is given by the following equation.

Substituting Eq. (3) and Eq. (4) into Eq. (5), we have

$$
\begin{aligned}
R & =W_{2} \cdot \mu^{\prime} \cdot\left(1-\frac{r_{2}}{r_{1}}\right) \\
& =W_{2} \cdot \mu^{\prime} \cdot n \cdots \cdots(6)
\end{aligned}
$$

If the slipping is brought about by applying the brakes on the ordinary truck, the running resistance will amount to a large value of $w_{2} \cdot \mu^{\prime}$. Further, the absorption ot braking energy and the subsequent heating of the wheels can not be neglected.
In our system, the retarding force on the slipping axle is nearly cancelled by the tangential force on the normal axle wheel and results in a small value as is given by $\mathrm{Eq}$. (6)

\section{Test Program}

\subsection{Design and construction of} the test truck

Figure 2 shows a side view of the test truck designed to fit into the currently used car. In order to give the load on the normal axle higher than that on the slipping axle, the distance from the center plate axis to the slipping axle is set at two times the value from it to the normal axle ( $b=2 a$ in Fig. 2), giving half of the normal axle load to the slipping axle. Each axle is connected to the corresponding propeller shaft through reduction gearing of the same design, and the propeller shafts are coupled by a clutch. As shown in Fig. 2, the diameters of the wheels on the normal and slipping axles are $910 \mathrm{~mm}$ and $860 \mathrm{~mm}$ respectively, and the initial value of $n$ is $5 \%$.

It was anticipated, as in case of the cefficient of adhesion (friction) $\mu$, that the surface condition of wheel tread would play a big role in $\mu^{\prime}$. Therefore, special pads for the tread lapping were provided for the slipping axle wheels. The pads are actuated independently of the brake shoes, and the required surface roughness can be obtained by applying suitable lapping pads while running. Besides, tread cleaners and rail watering devices are provided to investigate the effects of those factors upon $\mu^{\prime}$.

\subsection{Test on bench}

Before fitting into the car body, the truck was run on a test bench. The truck was set on the supporting wheels of $1200 \mathrm{~mm}$ diameter with rail profile in the bench, and run at the wheel speed equivalent to the train speed of $95 \mathrm{~km} / \mathrm{h}$ and at the constant rate of slipping of $5 \%$, in both modes of the clutch "On" and "Off".

\subsection{Test in JNR Ohmiya Factory yard}

After the design performance tests on the bench, the truck was fitted into a JNR MAYA 49 type passenger car. The car ran on a $1.4 \mathrm{~km}$ test track in JNR Ohmiya Factory yard, hauled by a locomotive. The normal axle was set at the leading position in the direction of travel. Diameter of the normal axle wheels under the

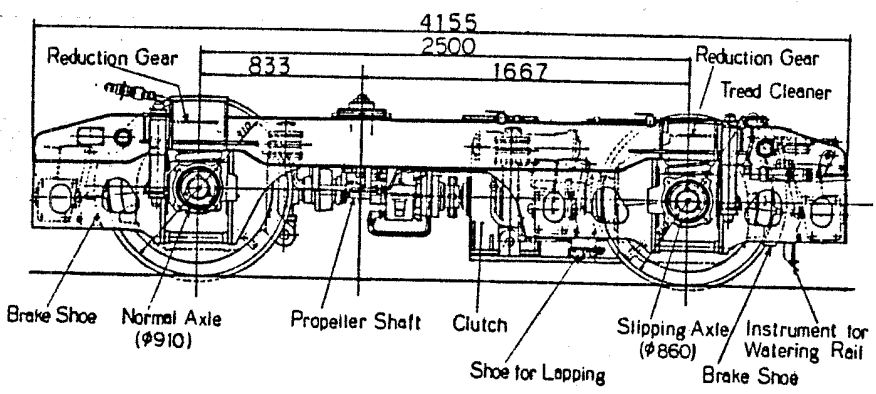

Fig. 2 Side view of the test truck 
$139.1 \mathrm{kN}$ load was kept unchanged at $910 \mathrm{~mm}$, while three dilameters of 860,814 and $774 \mathrm{~mm}$ were tried successively for the slipping axle wheels to give three nvalues of 5,10 and $15 \%$ to the slipping axle. Those diameters were obtained by turning on a wheel lathe. While running, surface roughness of the slipping wheel tread was maintained constant at about $5 \mathrm{~s}$ by application of the lapping pads from time to time.

\subsection{Measurement of the coefficient of slipping adhesion}

Load $W_{2}$ on the slipping axle and conflict torque $T$. should be detected in order to obtain the value of $\mu^{\prime}$ given by Eq. (2). As the fluctuation of the axle load while running was practically small, it might have been sufficient to measure $T$ only, assuming $W_{2}$ as constant. However, $W_{2}$ was measured continually while running by means of strain gages set on the wheel centers on both sides of the axle $D_{2}$, and $T$ by the one set on the output shaft of the clutch, to make sure of them. The obtained data of $W_{2}$ were put into an analogue computer which put out the value of $\mu^{\prime}$ continually while running.

\section{Test Results and Discussion}

\subsection{Bench test}

Results of the bench tests were sattisfactory. No sign of abnormal vibration or heat generation was observed at the various structural parts. In Fig. 3 is given an example of data obtained in the tests, wherein the relation between the speed $V$ and $\mu^{\prime}$ at $n=5 \%$ was investigated for various tread surface roughness and watering conditions. As far as the test results are concerned, it is clear that

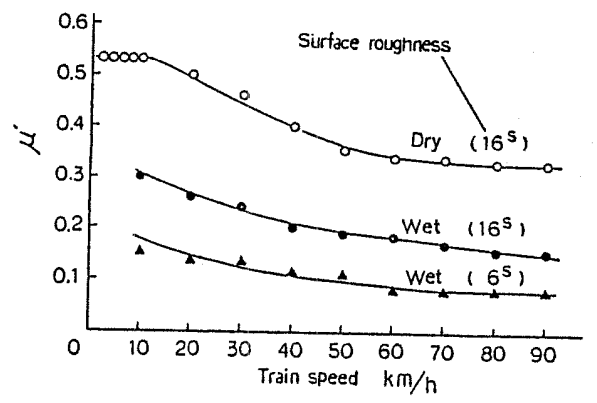

Fig. 3 Relation between $\mu^{\prime}$ and train speed at constant rate of slipping: $n=5 \%$ results are concerned, it is clear that the speed, degree of dryness and roughness of the wheel tread are closely related to $\mu^{\prime}$. Values of $\mu^{\prime}$ when watered are about half of $\mu^{\prime}$ when dry. $\mu^{\prime}$ increases with roughness. In the low speed range $(v:$ lower than $10 \mathrm{~km} / \mathrm{h}, \mathrm{dry}), \mu^{\prime}$ shows approximately constant ceiling values.

\subsection{Test run in Ohmiya Factory yard}

1) Stability of running

As our truck is of a special design, its preliminary tests were done prior to running on JNR main lines to examine its stability and detect abnormality in its parts while running.

Figure 4 shows an example of the records obtained at $n=5 \%$ on watered rails. In it are given; conflict torque $T$, speed of the wheels on the normal axle $D_{1}$ and slipping axle $D_{2}$, differential speed between $D_{1}$ and $D_{2}$, vertical load $P$ and side force $Q$ on the left (L) and right (R) side wheels of axle $D_{2}$, and pressure in the tread brake cylinder (BC) for $D_{1}$ axle wheels. Smooth changes in the speeds of $D_{1}$ and $D_{2}$ axle wheels and differential speed show the stable slipping runs. Fluctuation in the differential speed took place only when starting and stopping due to the vibration of $\mathrm{D}_{2}$. But there was no problem at high speeds.

Although some reciprocal fluctuations are observed in $P$ on the left and right wheels on $D_{2}$, both $Q$ and the derailing coefficient $Q / P$ are within the permissible limits and the running condition is quite stable. The minute vibration in $T$ is due to torsion of the propeller shafts. Its frequency coincided with the rotation speed of the propeller shafts.

In place of the measured values of $T$, corresponding values of $\mu^{\prime}$ are used in the figure, assuming that the load on axle $D_{2}$ remains practically constant. In stantaneous large fluctuations in the measured $T$ are the noises received by the FM telemeter used for the measurement. The (mean) value of $T\left(\mu^{\prime}\right)$ shows marked increase along the two curves located at the distances $1.5 \mathrm{~km}$ and $1.8 \mathrm{~km}$ from Ohmiya Station. We first supposed that $\mu^{\prime}$ was closely related to the curvature. However, upon the subsequent examination of the rail surface, oil was found on the rails over a wide range of the test track except the above mentioned two curves. Presumably, the oil was dropped from a Diesel locomo-

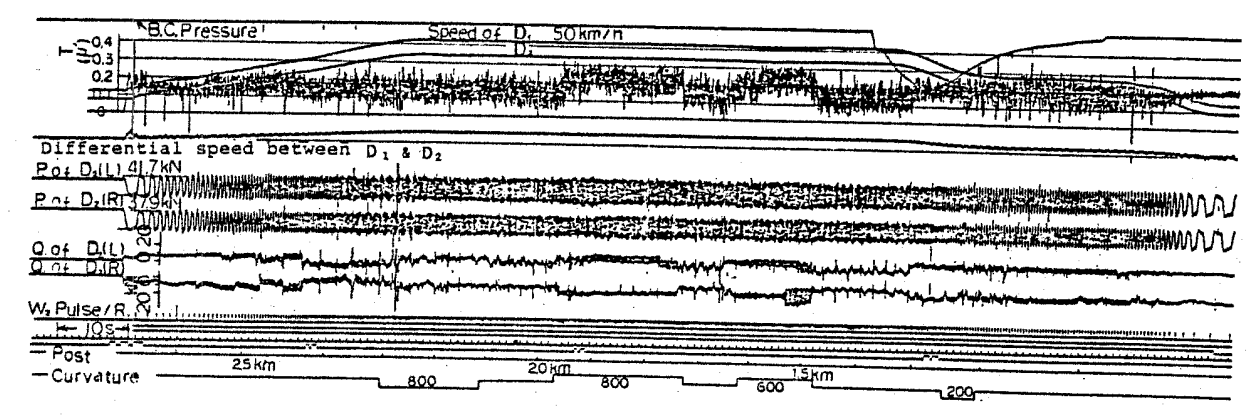

Fig. 4 An example of recorded running conditions of the test truck ( $n=5 \%$, rails watered) 
tive which underwent test runs before our tests. And, as the above two curves were located at the middle of the test track where the locomotive passed by at high speed, the oil drops were thrown away of $f$ the rails by the centrifugal effect when passing the curves at high speed. In the tests carried out later when the trace of dropped oil was no more detected, no marked difference in $\mu^{\prime}$ was observed between those curves and other parts of the test track. Therefore, this should be regarded as exceptional. It must also be added that no correlation was observed between $\mu^{\prime}$ and the fluctuation of load $P$ on the right and left side wheels or the side force $Q$, so far as the obtained data are concerned.

2) Change of $\mu^{\prime}$ at an identical spot

Figure 5 shows the result of investigation into the change of $\mu^{\prime}$ at an identical spot and at a constant $n$-value of $10 \%$. Tests were carried out in order of three groups: Nos. $1-4,4-7$, and 10 - 11. Watering was done on tyres for the groups Nos. 2 and 3 . Test results show that the runs within a same group under almost same condition - for example, Nos. 1 and 4, Nos. 5 and $6-$ yield reproduci- ble data in general, whereas different trends in $\mu^{\prime}$ are observed between the results of tests belonging to the different goups respectively, even when the spot, speed or rail watering conditions are the same. Among the results, it is presumed that the low values of $\mu^{\prime}$ in the tests Nos. 4 and 11 at the same spots near the starting and terminal points were because of the effect of the remaining water used in the preceding runs. Other variations in $\mu^{\prime}$ should be attributed to some changes which had taken place on the ground side.

The rails are burnished, even though minutely, by slipping runs. Fig. 6 shows the surface condition transferred by means of adhesive tapes from a rail before and after the test runs carried out at $n$-value of $15 \%$ on a different day. The left side of it indicates the rail before test, while the right side does the same spot after repeated 9 runs. Although not so clearly distinguished in the figure, the right side shows considerably less rust than the left, suggesting the above mentioned burnishing effect.

It is presumed from the above, that the burnishing effect of slipping runs contributed to the improvement of $\mu^{\prime}$.

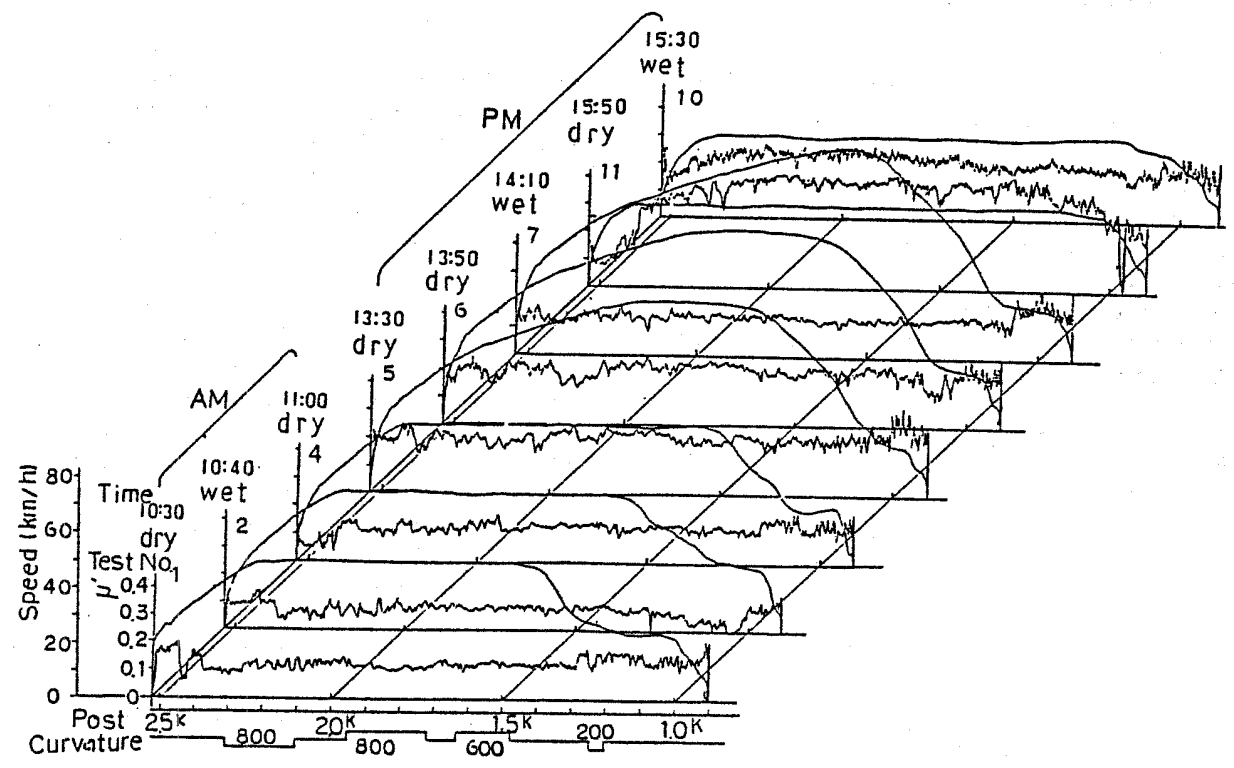

Fig. 5 Change of $\mu^{\prime}$ at an identical spot

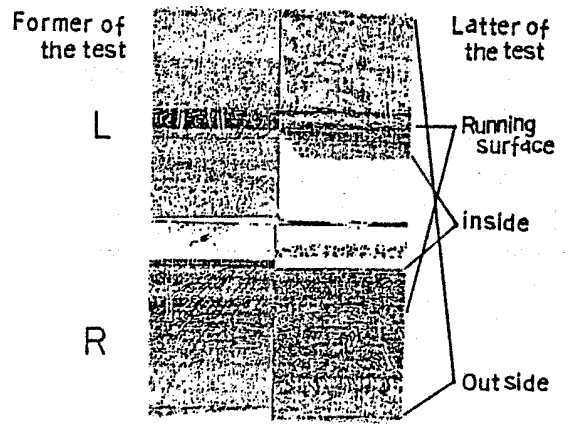

Fig. 6 Rail surface condition before and after test runs $(n=15 \%)$

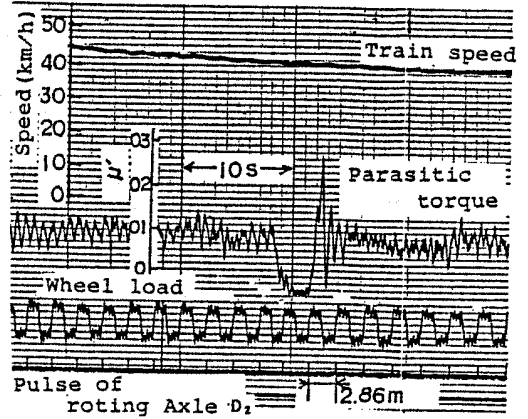

Fig. 7 An example of vanished adhesion $\left(\mu^{\prime}=0\right)$ 
However, from this presumption only, we cannot explain why the values of $\mu^{\prime}$ were almost the same in the case when the test runs were continually repeated under an identical condition, for example, tests No. 5 and No. 6 in Fig. 5. Along the test track in the yard, unlike the lines in service, rail surfaces were covered with considerable amount of rust which would give some effect in the course of time. Investigation into the real state of affairs is a subject left in the future. Next, some spots with extremely low $\mu^{\prime}$ were detected along the track near its terminal points where considerable amount of water remaining on the rails was expected, as shown by the tests Nos, 2 and 11. Detail of test No. 2 is given in Fig. 7 as an example. In order to demonstrate the state of sharp changes in $\mu^{\prime}$, the coefficient of slipping adhesion converted from the conflict torque $T$ on the propeller shaft is given in the figure. As shown in it, although instantaneously, $\mu^{\prime}$ entirely drops to zero - due to the vibration of propeller shaft system, $\mu^{\prime}$ momentarily drops below zero - proving the existance of spots where $\mu^{\prime}$ vanishes.

\section{3) Effect of watering}

In order to investigate the change in adhesion when the rails were watered (rate of watering $=2.3 \mathrm{~L} / \mathrm{min} / \mathrm{side}$ ), test runs were carried out at approximately the same speed and rate of slipping $(n=5 \%)$, under three watering conditions of wet (watered all the way), intermittent and dry. The results are shown in Fig. 8, wherein the "Train speed" curve is of the intermittent watering. As aforementioned, $\mu^{\prime}$ fluctuated sharply at specific spots due to the oil dropped on the rails on the day of test with slip of $5 \%$. In the data obtained under such circumstances, fluctuations due to watering and other unrelated factors such as oil drops on the rails, etc. are involved. Therefore, it is difficult to identify the effect of watering. However, as seen in the figure, $\mu^{\prime}$ falls down consistently about 0.1 during the intermittent watering. On the other hand, difference in the value of $\mu^{\prime}$ between dry and wet (watered all the way) is not so marked and the reduction in $u^{\prime}$ resulting from watering was only about 0.03 . It must be noted that the test runs were done first in dry condition and next in wet (all the way), but two extra running tests for other projects

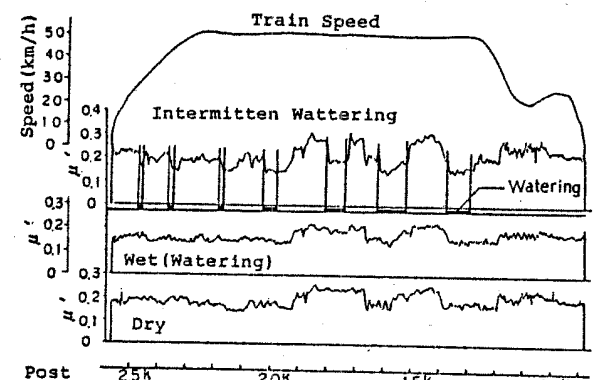

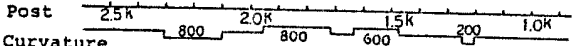

Fig. 8 Effect of watering upon the changes in $\mu^{\prime}$ were interposed between our dry and wet tests, and as the rails were burnished in the interposed tests, an increase of $\mu^{\prime}$ was brought about in the succeeding wet test presumably. As it is supposed that the rail condition could not be changed quickly during the intermittent watering runs, reduction of $\mu^{\prime}$ in the intermittent runs may be attributed to the watering on the rails.

\section{4) Effect of the rate of slipping}

It has been generally said that $\mu^{\prime}$ varies in connection with $n$ or the speed of slip ${ }^{3)}$. Accordingly, the test truck was run on a specified section on the test track at an identical speed in dry condition, and $\mu^{\prime}$ was measured under various rates of slipping. An example of the test results is given in Fig. 9 .

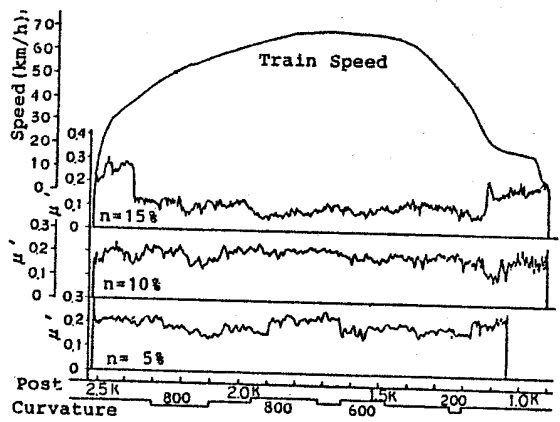

Fig. 9 Relation between $n$ and $\mu^{\prime}$

It is observed in the figure that, $\mu^{\prime}$ at $n=15 \%$ is generally lower than in the other cases. However, when the case of $n=10 \%$ is compared with that of $n=5 \%$ $\mu^{\prime}$ at higher $n$ is not always lower in its values. Further, although not illustrated, values of $\mu^{\prime}$ higher than 0.3 had really been recorded at $n=15 \%$ and the speed of $50 \mathrm{~km} / \mathrm{h}$. As already stated, $\mu^{\prime}$ is largely affected by the surface condition of rails. Therefore, strict control of the rail condition will be required for close examination of the relation between the coefficient of slipping adhesion $\mu^{\prime}$ and the rate of slipping $n$.

\section{Summary}

On a special bogie truck built to analyze the real state of the coefficient of slipping adhesion on JNR main lines, bench tests were first carried out. The truck was then fitted into a passenger car, and running tests were made on a test track in JNR Ohmiya Factory under diversified slipping conditions. The test results are summarized in the following.

1) Performance of the test truck during the slipping runs is always stable. By means of running it on the main lines, the coefficient of slipping adhesion between the rails and wheels at the preset rate of slipping can be measured continuously and consistently.

2) By virtue of the above means, real state of the coefficient of slipping adhesion fluctuating continuously in the 
direction of travel on the rails has been made clear for the first time.

3) The coefficient of slipping adhesion fluctuates continuously within a degree of 0.1 . In some cases, sharp changes of this kind were observed during a few meters' travel of the truck.

4) It is likely that the coefficient of slipping adhesion falls down nearly to zero in the sections where a large amount of water stays on the rails. However, such sections are not long, and no reproducibility was obtained.

5) Even when a wheel-axle system is repeatedly run on an identical spot in an identical condition, measured values of the coefficient of slipping ahhesion are not always the same.

6) By running repeatedly a wheel-axle system with about $70 \mathrm{kN}$ axle load several times at the slipping rate of 5 to 15\%, surface of the rails is burnished, and the coefficient of slipping adhesion increases.

7) BY watering the rails, the coefficient of slipping adhesion is decreased by about a maximum value of 0.1 .

\section{Acknowledgements}

In the course of author's investigation, Mr. S. Nishimura, Mr. M. Wakita,
Mr. T. Noda, and many concerned members of Osaka Steel Works of Sumitomo Metal Industries, Ltd. Uyedasa Foundry, JNR Ohmiya Factory, JNR Rolling Stock Design office and Car Performance Research Laboratory of JNR RTRI. rendered him valuable advice and assistance. To these gentlemen, companies and institutes, the author would like to express his most sincere gratitude.

\section{References}

1) Carter, F. W., Proc. Roy. Soc. Series A, Vol. 112 (1926), p.151.

2) E.g. Hosaka, Trans. Japan Soc. Mech. Engrs. (in Japanese), Vol. 17, No. 61 (1951), p. 161 .

3) Seki, et al., Journal Soc. Elec. Engrs. (in Japanese), Vol. 80, No. 860, p.606.

4) Nagase, K., Text for Education Course, Japan Soc. Mech. Engrs. (in Japanese), No. 412 (1975), p. 58 .

5) Nagase, K., JREA. (in Japanese), Vol. 20, No. 11 (1977), P.11695.

6) Nagase, K., et al., Railway Cybernetics Conf., No. 18 (1981), Paper No. 424 (in Japanese), p. 250 .

7) Uchimura, JREA. (in Japanese), Vol. 7, No. 1 (1964), p. 3177 . 